\title{
Tight junction protein 1 is regulated by transforming growth factor- $\beta$ and contributes to cell motility in NSCLC cells
}

\author{
So Hee Lee ${ }^{1,3}$, A Rome Paek ${ }^{1}$, Kyungsil Yoon ${ }^{2}$, Seok Hyun Kim ${ }^{1}$, Soo Young Lee ${ }^{3}$ E Hye Jin You ${ }^{1, *}$ \\ ${ }^{1}$ Cancer Cell and Molecular Biology Branch, Div. of Cancer Biology, ${ }^{2}$ Lung Cancer Branch, Div. of Translational and Clinical Research I, \\ National Cancer Center, Goyang 410-769, ${ }^{3}$ Division of Molecular Life Sciences, Ewha Womans University, Seoul 120-750, Korea
}

Tight junction protein 1 (TJP1), a component of tight junction, has been reported to play a role in protein networks as an adaptor protein, and TJP1 expression is altered during tumor development. Here, we found that TJP1 expression was increased at the RNA and protein levels in TGF- $\beta$-stimulated lung cancer cells, A549. SB431542, a type-I TGF- $\beta$ receptor inhibitor, as well as SB203580, a p38 kinase inhibitor, significantly abrogated the effect of TGF- $\beta$ on TJP1 expression. Diphenyleneiodonium, an NADPH oxidase inhibitor, also attenuated TJP1 expression in response to TGF- $\beta$ in lung cancer cells. When TJP1 expression was reduced by shRNA lentiviral particles in A549 cells (A549-sh TJP1), wound healing was much lower than in cells infected with control viral particles. Taken together, these data suggest that TGF- $\beta$ enhances TJP1 expression, which may play a role beyond structural support in tight junctions during cancer development. [BMB Reports 2015; 48(2): 115-120]

\section{INTRODUCTION}

Transforming growth factor- $\beta$ (TGF- $\beta$ ) superfamily members, which include well-known growth factors, are involved in a variety of cellular processes, such as cell proliferation and differentiation. TGF- $\beta$ signaling is initiated by ligand binding to type I, II, and III TGF- $\beta$ receptors. Then, the type II TGF- $\beta$ receptor forms a complex and activates the type I TGF- $\beta$ receptor to initiate intracellular signaling. The type I TGF- $\beta$ receptor phosphorylates Smad2 and Smad3 directly, which form a complex with Smad 4 and accumulate in the nucleus, and regulate gene expression (1-4). In addition to the Smad-dependent canonical pathway, crosstalk and signaling through Smad-independent signaling pathways have been reported (5-7). It is

*Corresponding author. Tel: +82-31-920-2206; Fax: +82-31-9202206; E-mail: hjyou@ncc.re.kr

http://dx.doi.org/10.5483/BMBRep.2015.48.2.035

Received 13 February 2014, Revised 12 March 2014, Accepted 10 July 2014

Keywords: TGF- $\beta$, TJP1, EMT, Motility, ROS not fully understood how TGF- $\beta$ signals in these pathways. In advanced cancers, TGF- $\beta$ displays a tumor-promoting effect by inducing an epithelial-mesenchymal transition (EMT), which enhances invasiveness and metastasis. Generally, EMT is characterized by a loss of cell-cell adhesion and apical-basal polarity and a gain in motility (8).

Epithelial cells allow the separation of different tissues and body compartments by developing cell surface domains called junctions, which are important for the biogenesis, maintenance, and function of epithelia (9-11). Tight junctions, the most apical component of the intercellular junctional complex, form a barrier to the diffusion of molecules from the lumen to the parenchyma and regulate the diffusion of various cellular macromolecules between the apical and basolateral plasma membranes. Thus, a loss of barrier function due to growth factors or cytokines is closely related to pathophysiological processes, leading to tumors and retinopathy, for example $(11,12)$.

One of the tight junction proteins, "tight junction protein 1" (TJP1, zonula occludens-1, ZO-1), is responsible for the protein networks between actin and integral tight junction proteins, such as occludin and claudins $(13,14)$, in the tight junction, as well as cell integrity. Thus, a loss of tight junction barrier function due to TJP1 dysfunction has been related to cancer metastasis (9). However, the role of TJP1 expression in cancer has been controversial. Generally, TJP1 is considered a tumor suppressor, supported by various studies (15-17). In contrast, TJP1 expression and localization has also been reported to be altered in pancreatic cancer, colorectal cancer, melanoma, and non-small cell lung cancer (NSCLC) (18-21), suggesting a role for TJP1 in tumor progression. While accumulating data suggests a role for TJP1 in cancer, the detailed mechanism by which TJP1 expression might be regulated in cancer remains unclear.

Here, we investigated the possibility that TGF- $\beta$ influenced TJP1 expression and sought to identify mediators of TGF- $\beta$-induced TJP1 expression in lung cancer cells. We also performed TJP1 knockdown experiments to determine whether TJP1 is involved in cancer cellular processes, such as migration or EMT. 


\section{RESULTS}

TJP1 is increased in TGF- $\beta$-stimulated lung cancer cells Previously, we showed that TGF- $\beta$ has an effect on EMT and motility in lung cancer cells (22). To verify the effect of TGF- $\beta$ on cell adhesion and junctional proteins in A549 cells, we first examined the expression of E-cadherin and $\mathrm{N}$-cadherin in TGF- $\beta$-stimulated A549 lung cancer cells (Fig. 1A, B). TGF- $\beta$ increased $\mathrm{N}$-cadherin expression and decreased $\mathrm{E}$-cadherin expression in A549 lung cancer cells, as expected. In terms of tight junction proteins, TJP1 was increased in response to TGF- $\beta$ (Fig. 1A), while TJP3 was decreased at the RNA level (data not shown). Because TJP1 decreased in response to TGF- $\beta$ in various cancer cell lines $(15,23,24)$, we conducted additional experiments to confirm the effects of TGF- $\beta$ on TJP1 ex-

A

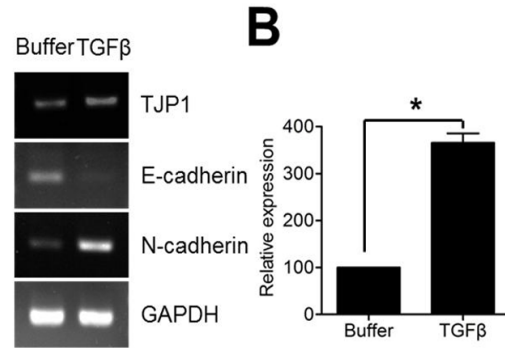

C

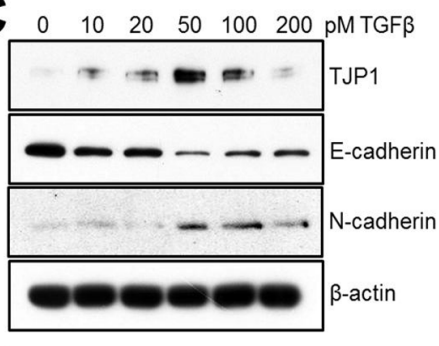

D $\begin{array}{llllll}0 & 3 & 6 & 12 & 24 & 48 \mathrm{~h}, 50 \mathrm{pM} \text { TGF } \beta\end{array}$

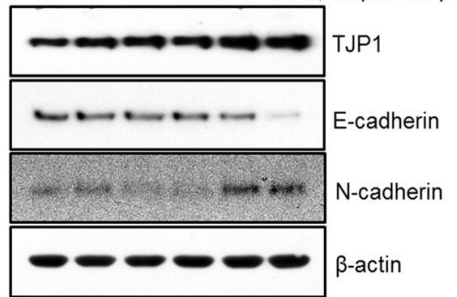

Fig. 1. TGF- $\beta$ induces TJP1 expression in A549 lung carcinoma cells. Subconfluent cells were exposed to TGF- $\beta$ for 24 h, harvested, lysed, and analyzed for TJP1, E-cadherin, N-cadherin, and GAPDH expression by (A) RT-PCR and (B) real-time PCR in A549 cells. Subconfluent cells were exposed to $(C)$ various concentrations of TGF- $\beta$ for $24 \mathrm{~h}$ or to (D) $50 \mathrm{pM}$ TGF- $\beta$ for various time periods, as indicated, in A549 cells, and analyzed for TJP1, E-cadherin, N-cadherin, and $\beta$-actin expression by immunoblotting. All results are representative of at least three independent experiments. Data are expressed as means \pm SE. Statistical significance was assessed using paired Student's t-tests (*P $<0.0001)$. pression in A549 lung cancer cells. As shown in Fig. 1C and $D$, TGF- $\beta$ induced TJP1 expression, beginning at $10 \mathrm{pM}$ and peaking at $50 \mathrm{pM}$ TGF- $\beta$. In time-course experiments, TJP1 expression reached a maximum at $24 \mathrm{~h}$ in A549 lung cancer cells. Induction of TJP1 in response to TGF- $\beta$ was also seen in $\mathrm{NCl}-\mathrm{H} 596$ and $\mathrm{A} 427$ human lung carcinoma cell lines (Fig. 4C), suggesting a role for TGF- $\beta$ on TJP1 expression in lung cancer.

\section{p38 kinase, NADPH oxidase, and type I TGF- $\beta$ receptor inhibitors reverse TGF- $\beta$-induced TJP1 expression in A549 lung cancer cells}

To assess the regulatory mechanism for TJP1 expression in response to TGF- $\beta$ in A549 human lung carcinoma cells, cells were treated with TGF- $\beta$ in the presence of SB431542, a type I TGF- $\beta$ receptor inhibitor, SB203580, a p38 kinase inhibitor, PB98059, a MEK1 inhibitor, SP600126, a c-Jun amino-terminal kinase (JNK) inhibitor, diphenyleneiodonium (DPI), an NADPH oxidase inhibitor, $\mathrm{N}$-acetyl cysteine (NAC), a reactive oxygen species scavenger, wortmannin, a phosphatidylinositol 3-kinase (PI3-kinase) inhibitor, and dimethyl sulfoxide (DMSO) for $24 \mathrm{~h}$. Inhibitors were added $30 \mathrm{~min}$ prior to TGF- $\beta$ addition. SB431542, SB203580, NAC, and DPI attenuated TJP1 expression in A549 lung carcinoma cells 3 (Fig. 2) while PD98059, SP600125, and wortmannin did not (data not

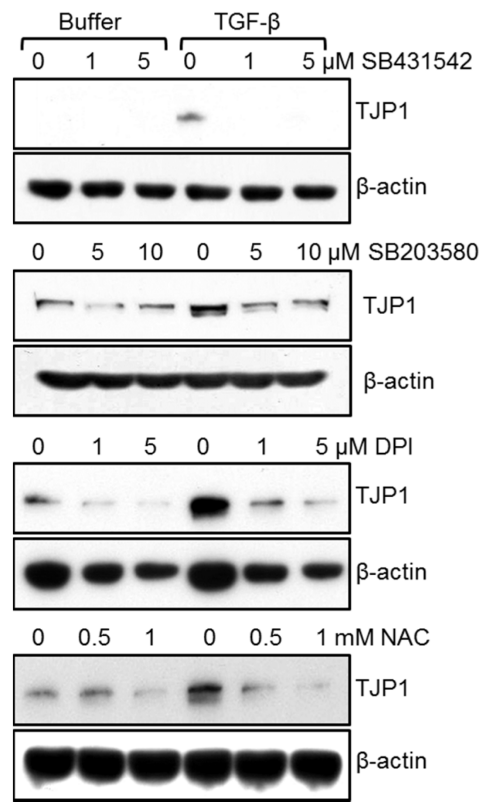

Fig. 2. SB431542, a type I TGF- $\beta$ receptor inhibitor, SB203580, a p38 kinase inhibitor, DPI, an NADPH oxidase inhibitor, and NAC, a ROS scavenger, attenuated TGF- $\beta$-mediated TJP1 expression in A549 cells. Subconfluent cells were treated with 50 pM TGF- $\beta$ for $24 \mathrm{~h}$ in the presence of the indicated amounts of buffer, SB431542, SB203580, DPI, or NAC and evaluated for TJP1 expression by immunoblotting. All results shown are representative of at least three independent experiments. 


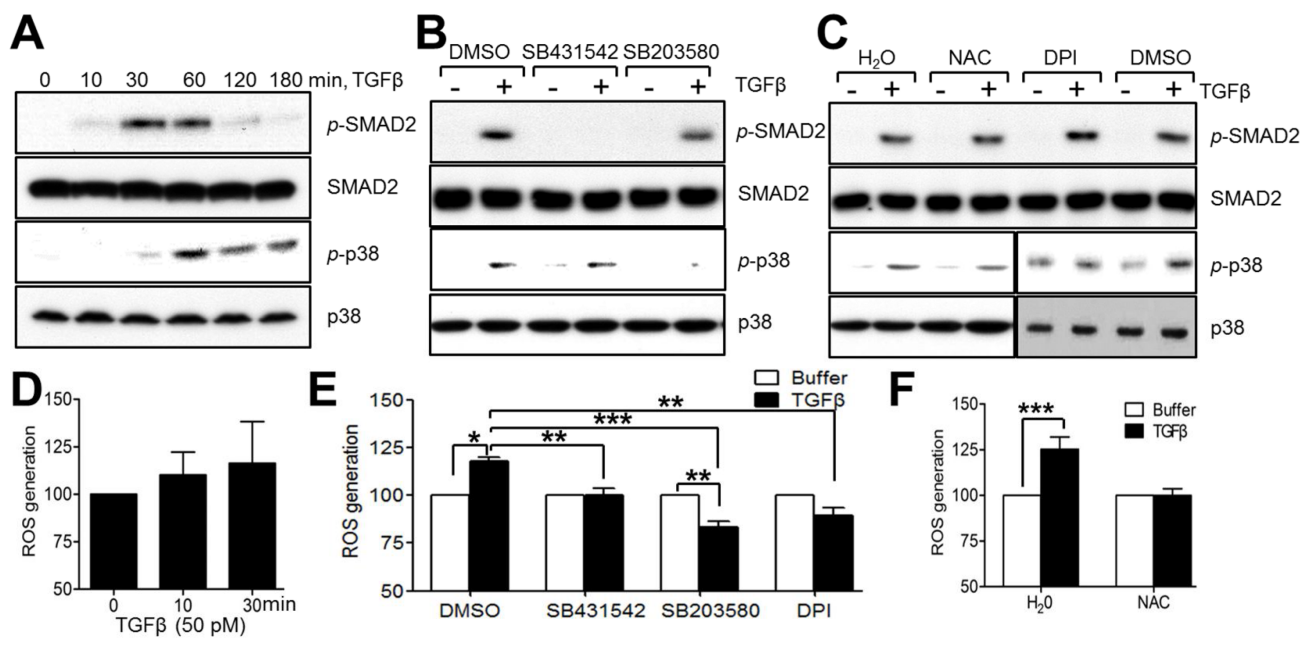

Fig. 3. p38 kinase, ROS, and type I TGF- $\beta$ receptor pathways did not show significant crosstalk in A549 lung carcinoma cells. (A) Subconfluent cells were treated with TGF- $\beta(50 \mathrm{pM})$ for the time periods indicated and evaluated by immunoblotting to analyze TGF- $\beta$-induced signaling in A549 cells. (B, C) Subconfluent cells were treated with TGF- $\beta$ (50 pM) for 10 min in the presence of various inhibitors (10 $\mu \mathrm{M}$ SB431542, $10 \mu \mathrm{M}$ SB203580, $1 \mathrm{mM}$ NAC, $5 \mu \mathrm{M}$ DPl) or vehicles (DMSO, $\mathrm{H}_{2} \mathrm{O}$ ), and evaluated by immunoblotting. (D) Subconfluent cells were treated with TGF- $\beta$ for 0-30 min. DCF fluorescence was measured using a FACSCalibur. (E, F) Subconfluent cells were starved and treated with TGF- $\beta(50 \mathrm{pM})$ for $30 \mathrm{~min}$ in the presence of SB431542, SB203580, DPI, NAC, or vehicles (DMSO, $\left.\mathrm{H}_{2} \mathrm{O}\right)$. Inhibitors were added $30 \mathrm{~min}$ prior to TGF- $\beta$ treatment. All results shown are representative of at least three independent experiments. Data are expressed as means \pm SE. Statistical significance was assessed using paired Student's $t$-tests $\left({ }^{*} \mathrm{P}<0.0001,{ }^{* *} \mathrm{P}<0.01,{ }^{* * *} \mathrm{P}<0.05\right)$.

shown). These results suggest that the type I TGF- $\beta$ receptor, p38 kinase, and ROS may be involved in TJP1 expression in response to TGF- $\beta$. To further confirm the role of the type I TGF- $\beta$ receptor, p38 kinase and ROS in TGF- $\beta$ signaling-mediated TJP1 expression, we examined downstream signaling activation in TGF- $\beta$-stimulated A549 cells (Fig. 3A). As expected, Smad2 was phosphorylated after $10 \mathrm{~min}$ and reached a maximum at 60 min in response to TGF- $\beta$ in A549 lung cancer cells. p38 kinase was also phosphorylated in response to TGF- $\beta$, occurring at $30 \mathrm{~min}$ and lasting for $3 \mathrm{~h}$. We did not observe any significant change in the phosphorylation status of extracellular signal-regulated kinase (ERK) or JNK in TGF- $\beta$-stimulated A549 lung cancer cells (data not shown). To examine any crosstalk between downstream signaling pathways, cells were treated with TGF- $\beta$ in the presence of SB431542, SB203580, DPI, NAC, or vehicles (DMSO or $\mathrm{H}_{2} \mathrm{O}$ ) for 10 min and then harvested for immunoblotting. SB431542 inhibited Smad2 phosphorylation markedly in response to TGF- $\beta$, but it did not affect p38 kinase phosphorylation by TGF- $\beta$ in A549 lung cancer cells (Fig. 3B). SB203580, a p38 kinase inhibitor, did not affect the phosphorylation of Smad2, indicating that Smad2, as well as p38 kinase, may be involved independently in TGF- $\beta$-mediated TJP1 expression in lung cancer cells. Recently, TGF- $\beta$ was reported to increase cellular ROS with the help of NADPH oxidase 4, contributing to cellular differentiation (25). Here, we observed ROS generation in response to TGF- $\beta$ in A549 lung cancer cells. Moreover, TGF- $\beta$-induced ROS generation was inhibited by DPI, an
NADPH oxidase inhibitor and NAC, a ROS scavenger (Fig. 3E, F). Additionally, neither DPI nor NAC altered the phosphorylation status of Smad2 (Fig. 3C), while ROS generation by TGF- $\beta$ was attenuated by SB431542 and SB203580 (Fig. 3E), indicating that ROS may contribute to TJP1 expression after activation of Smad 2 and p38 kinase in TGF- $\beta$-stimulated A549 lung cancer cells.

\section{TGF- $\beta$ induces TJP1 expression in lung cancer cells, contributing to cell motility}

To investigate the role of TJP1 in TGF- $\beta$-mediated signaling in A549 lung cancer cells, we generated A549-sh control and A549-sh TJP1 cell lines, expressing control and TJP1 targeting shRNA, respectively. TGF- $\beta$ treatment altered the expression of E-cadherin as well as $\mathrm{N}$-cadherin in both A549-sh control and A549-sh TJP1 cells, suggesting that TJP1 knockdown caused no significant effect on $\mathrm{E}$-cadherin or $\mathrm{N}$-cadherin expression in TGF- $\beta$-treated A549 lung cancer cells (Fig. 4A). TJP1 knockdown showed delayed wound healing in wound healing assays (Fig. 4B), suggesting a role for TJP1 in cell motility. To further confirm a role of TJP1 in cell migration and invasion, A549-sh control and A549-sh TJP1 cells were treated with TGF- $\beta$ or buffer for $24 \mathrm{~h}$, after which each group of cells was induced to invade through Matrigel-coated Transwell membranes (Fig. 4D). Consistent with the wound healing assay, A549-sh Control treated with TGF- $\beta$ for TJP1 induction showed more invaded cells than A549-sh Control cells treated with buffer. A specific role for TJP1 in cell invasion in A549 cells 


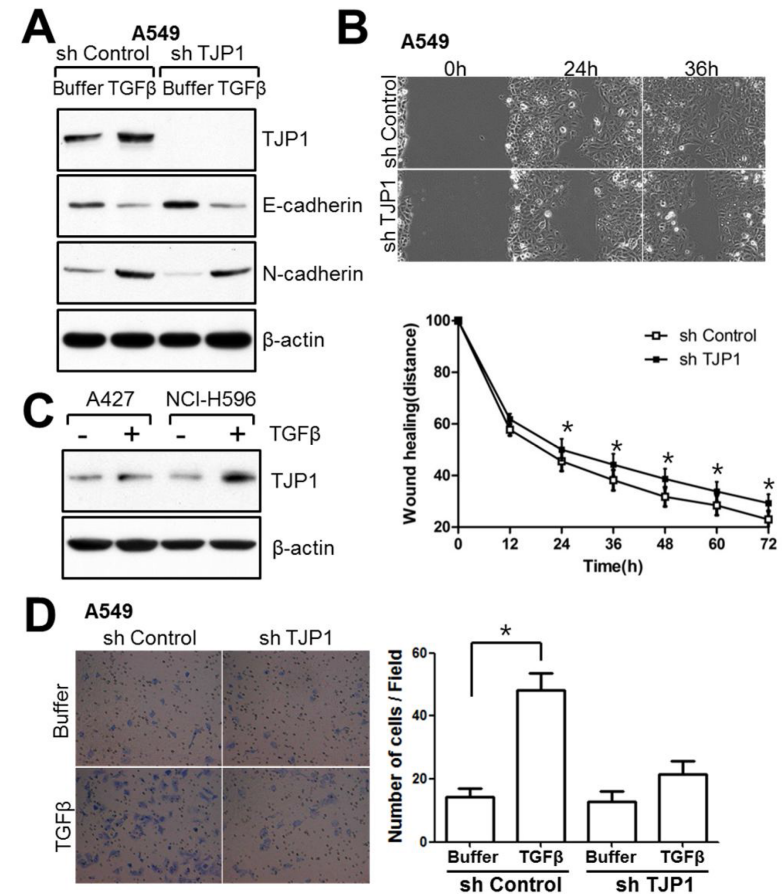

Fig. 4. TJP1 is increased in response to TGF- $\beta$ in lung cancer cells and contributes to cellular motility. (A) Subconfluent cells were treated with $50 \mathrm{pM}$ TGF- $\beta$ for $24 \mathrm{~h}$ and harvested for immunoblotting. (B) Cells were grown until fully confluent, and a uniform scratch was made down the center of the well. Digital images of the wound were obtained in 12-h intervals until $72 \mathrm{~h}$ (top), and the horizontal distance between both sides of the wound was measured and analyzed statistically (bottom). All results shown are representative of at least three independent experiments. Data are expressed as the means \pm SE. Statistical significance was assessed using paired Student's $t$-tests (*P $<0.0001$ ). (C) A427 and $\mathrm{NCl}-\mathrm{H} 596$ lung cancer cells were treated with 100 pM TGF- $\beta$ for $24 \mathrm{~h}$ and evaluated for TJP1 expression by immunoblotting. All results shown are representative of at least three independent experiments. (D) Cells were induced to invade through Matrigel- coated Transwell membranes. After $24 \mathrm{~h}$, invaded cells were fixed and stained. Digital images were taken for cell counting. All results shown are representative of at least three independent experiments. Data are expressed as the means \pm SE. Statistical significance was assessed using paired Student's $t$-tests $(P<0.0001)$.

was supported in that there were fewer invaded cells in A549-sh TJP1 (with TGF- $\beta$, no induction of TJP1) than A549-sh Control (with TGF- $\beta$, TJP1 induction). Also, TGF- $\beta$ induced TJP1 expression in other lung cancer cell lines, such as A427 and $\mathrm{NCIH} 596$ (Fig. 4C). Together, these results support a role for TJP1 in TGF- $\beta$-induced cancer progression in lung cancer.

\section{DISCUSSION}

The main finding of this study was that TJP1 increased in response to TGF- $\beta$ through Smad-dependent, p38 kinase, and ROS pathways, and that it contributed to cell motility in lung cancer cells. TJP1 functions as a scaffold protein at tight junc- tions, which are important for cellular polarity, especially in epithelia (9-11). Thus, expression of TJP1 is believed to be one of the characteristics of epithelial cells and is reported to decrease or disappear during EMT and cancer cell development. However, some studies suggest a role for TJP1 during cancer progression. For example, Balda and Matter reported that 'ZO-1-associated nucleic acid-binding protein' (ZONAB) was an interacting protein for TJP1 (26). In this study, ZONAB, a $Y$ box transcription factor, was shown to mediate ErbB-2 expression with the help of TJP1 in vivo, suggesting that TJP1 may act as more than just a structural protein in a variety of cellular processes through its binding proteins. Additionally, TJP1 is overexpressed in pancreatic ductal adenocarcinoma, suggesting a role for TJP1 in cancer progression, especially in metastasis (19). In human melanoma, TJP1 was shown to be upregulated and to contribute to invasion by association with $\mathrm{N}$-cadherin (21). Gilles et al. reported that TJP1 also played a role in the regulation of interleukin-8, a CXC chemokine family member, in breast cancer cells (27). These studies suggest a role for TJP1 in cancer invasion and metastasis; however, it remains to be determined how TJP1 might be involved in cancer cell malignancy. Recently, a role for TJP1 in mouse embryonic stem cells was explored by inactivating the TJP1 locus through homologous recombination, suggesting a role for TJP1 in mouse embryonic stem cell self-renewal and differentiation under certain conditions (28). These studies caused us to hypothesize that TJP1 might be increased in certain cancers, thus contributing to disease progression. Although a few studies have shown a role for TGF- $\beta$ on TJP1 expression, they did not show the crosstalk between Smad-dependent and independent pathways and TJP1 expression in TGF- $\beta$-stimulated lung cancer cells. They also did not clarify the regulatory mechanism by which TGF- $\beta$ increases TJP1 expression $(15,24)$. Here, we provide a regulatory mechanism by which TGF- $\beta$ affects TJP1 expression in three human NSCLC cell lines: A549, HCl-H596. and $\mathrm{A} 427$ cells.

There are still many questions to be addressed, in terms of cancer selectivity and correlation to cancer stage, among others. Together, our data show that TGF- $\beta$ upregulates the expression of TJP1, an adaptor protein that contributes to various cellular functions, including cell migration in lung cancer cells.

\section{MATERIALS AND METHODS}

\section{Materials and plasmids}

DMEM and RPMI 1640 were purchased from Hyclone (Logan, UT, USA). McCoy's 5A and defined fetal bovine serum (FBS) were from GIBCO (Life Technologies Corp., Grand Island, NY, USA). SB431542, NAC, SB203580, wortmannin, and diphenyleneiodonium (DPI) were purchased from Calbiochem (La Jolla, CA, USA). TGF- $\beta$ was from R\&D Systems, Inc. (Minneapolis, $M N$, USA). The mouse monoclonal antibody for $\beta$-actin was from Santa Cruz Biotechnology Inc. (Santa Cruz, CA, USA). Rabbit polyclonal antibodies against TJP1, E-cadherin, N-cad- 
herin, phospho-p38 kinase, p38 kinase, and HRP-conjugated anti-mouse and anti-rabbit antibodies were from Cell Signaling Technology Inc. (Beverly, MA, USA). Rabbit monoclonal antibodies specific for Smad2, and phospho-Smad2 were from Cell Signaling Technology Inc. Short hairpin (sh) RNA-lentiviral particles against human TJP1 and control lentiviral particles were from Santa Cruz Biotechnology Inc.

\section{Cell culture}

Human lung carcinoma A549 cells (CCL-185), A427 (HTB-53), and human lung adenosquamous carcinoma NCl-H596 (HTB-178) cells were obtained from the American Type Culture Collection. A549 and $\mathrm{NCl}-\mathrm{H} 596$ cells were maintained in RPMI 1640 media supplemented with $10 \%$ FBS. A427 cells were maintained in DMEM supplemented with $10 \%$ FBS. All cells were grown at $37^{\circ} \mathrm{C}$ in a humidified $5 \% \mathrm{CO}_{2}$ atmosphere.

\section{Isolation of RNA, RT-PCR, and real-time PCR}

Cells were treated with TGF- $\beta$ for the indicated time periods and harvested. Total cellular RNA was extracted with RNeasy kit (Qiagen, Valencia, CA, USA). The RNA was quantified by UV scanning, and samples $(5 \mu \mathrm{g})$ were reverse-transcribed at $42^{\circ} \mathrm{C}$ for $60 \mathrm{~min}$ in $50 \mu \mathrm{l}$ buffer $(10 \mathrm{mM}$ Tris- $\mathrm{HCl}, \mathrm{pH}$ 8.3, 50 $\mathrm{mM} \mathrm{KCl}, 5 \mathrm{mM} \mathrm{MgCl}$, and $1 \mathrm{mM}$ each of dATP, dCTP, dGTP, and dTTP) in the presence of oligo(dT) primer. The TJP1 sense primer 5'-GGAGAGGTGTTCCGTGTTGT-3' and antisense primer 5'-GAGCGGACAAATCCTCTCTG-3; (GenBank Accession No.: NM_175610.2) were used to generate a 253-bp product. The E-cadherin sense primer 5'-TGGAGAGACACTGCCAACTG-3' and antisense primer 5'-GGCTTTGGATTCCTCTC-ACA-3' (GenBank Accession No.: NM 004360) were used to generate a 251-bp product. To amplify the 248-bp glyceraldehyde 3-phosphate dehydrogenase (GAPDH) product, specific primers were used: sense primer $5^{\prime}$-GAGTCAACGGATTTGGTCGT-3' and antisense primer 5'-TTGATTTGGAGGGATC-TCG-3' (GenBank Accession No.: NM 002046). The PCR products were subjected to electrophoresis, visualized with ethidium bromide, and photographed using the GelDoc program (Bio-Rad, Chicago, IL, USA).

For real-time PCR quantification, reactions were conducted using the LightCycler 480 SYBR Green I Master (Roche Diagnostics Corp., Indianapolis, IN, USA) following the manufacturer's instruction with various amounts of template cDNA in a $20-\mu \mathrm{l}$ final volume for 40 cycles. Samples were normalized to GAPDH and the $\Delta \Delta C_{t}$ methods was used to calculate fold expression changes of mRNA (29).

\section{Immunoblotting}

Protein samples were subjected to SDS-PAGE, followed by transfer to polyvinylidene difluoride membranes. Membranes were then blocked, incubated for $2 \mathrm{~h}$ with primary antibody, followed by $1 \mathrm{~h}$ with HRP-conjugated anti-mouse or rabbit antibody. The blots were developed with an enhanced chemiluminescence kit (West-ZOL plus, Intron Biotechnology Inc.,
South Korea).

\section{Measurement of intracellular ROS by flow cytometry}

Subconfluent cells were treated with 50 pM TGF- $\beta$ for the time periods indicated. Then, cells were washed with warm PBS, trypsinized, and quickly analyzed for green fluorescence by flow cytometry, as described previously (30). For ROS detection, 2', $7^{\prime}$ dichlorodihydrofluorescein diacetate $\left(\mathrm{H}_{2} \mathrm{DCFDA}, 10\right.$ $\mu \mathrm{M})$ was added 10 min before harvest, and the analysis was performed with a FACSCalibur (Becton-Dickinson, Mountain View, CA, USA) with the NCC FACS operator. In some experiments, cells were pretreated with inhibitors such as SB431542, SB203580, DPI, or DMSO 30 min prior to TGF- $\beta$ treatment. The arithmetic/geometric mean fluorescence channel (Geo MFC) was derived with CellQuest.

\section{shRNA-mediated silencing of human TJP1 in A549 cells}

For stable expression of shRNA against TJP1 through lentiviral infection, subconfluent A549 cells were incubated with Polybrene $(5 \mu \mathrm{g} / \mathrm{ml})$ for $1 \mathrm{~h}$ before the addition of the lentiviral vector. After $24 \mathrm{~h}$, the medium was replaced and cells were grown for 1 day. A549-sh control and A549-sh TJP1 stable cell lines were selected in $5 \mu \mathrm{g} / \mathrm{ml}$ puromycin dihydrochloride. To avoid clonal variation, we pooled individual infectants for each stable cell line produced by infection.

\section{Wound-healing assay}

A549-sh control and A549-sh TJP1 cells were grown in 6-well plates for $48 \mathrm{~h}$ until the cells were fully confluent. A uniform scratch was made down the center of the well using a sterile micropipette tip, followed by washing with PBS to remove non-adherent cells. Digital images of the wound were obtained every $12 \mathrm{~h}$ at $\times 10$ magnification using the NCC cell observer system (Axiovert 200M; Carl Zeiss Inc., Germany). The horizontal distance between both wound sides was measured.

\section{Invasion assay}

First, the upper compartment of an 8- $\mu \mathrm{m}$ Transwell $(6.5 \mathrm{~mm}$ diameter; Costar Corp., Cambridge, MA, USA) was coated with Matrigel $(1 \mathrm{mg} / \mathrm{ml})$ before starting the assay. Cells $\left(10^{4}\right.$ cells) were suspended in RPMI 1640 and placed in the upper compartment of the Transwell and the lower compartment was filled with RPMI 1640 supplemented with 10\% FBS. After 24 $\mathrm{h}$, the filter was washed with PBS and fixed with methanol. Migrated cells on the filter membrane were stained using a Diff-Quik Stain Kit. Each assay was conducted at least three times, and three random fields from a $\times 20$ magnification were analyzed for each filter membrane.

\section{Statistical analyses}

All data are expressed as percentages of the control and shown as means \pm standard error (SE). Statistical comparisons between groups were made using paired $t$-tests with the Prism 5.0 statistical software (GraphPad. Software Inc., San Diego, 
CA, USA). Values of $\mathrm{P}<0.05$ were considered to indicate statistical significance.

\section{ACKNOWLEDGEMENTS}

This work was supported in part by grants from the National Cancer Center to HJ You (NCC1410120) and in part by the Basic Science Research Program through the National Research Foundation of Korea (No. 2010-0022961, to HJ You).

\section{REFERENCES}

1. Bierie B and Moses HL (2006) Tumour microenvironment: TGFbeta: the molecular Jekyll and Hyde of cancer. Nat Rev Cancer 6, 506-520

2. Gordon KJ and Blobe GC (2008) Role of transforming growth factor-beta superfamily signaling pathways in human disease. Biochim Biophys Acta 1782, 197-228

3. Macias-Silva M, Abdollah S, Hoodless PA, Pirone R, Attisano $L$ and Wrana JL (1996) MADR2 is a substrate of the TGFbeta receptor and its phosphorylation is required for nuclear accumulation and signaling. Cell 87, 1215-1224

4. Massague J, Blain SW and Lo RS (2000) TGFbeta signaling in growth control, cancer, and heritable disorders. Cell 103, 295-309

5. Moustakas A and Heldin CH (2005) Non-Smad TGF-beta signals. J Cell Sci 118, 3573-3584

6. Song K, Wang H, Krebs TL and Danielpour D (2006) Novel roles of Akt and mTOR in suppressing TGF-beta/ALK5-mediated Smad3 activation. EMBO J 25, 58-69

7. Watanabe $\mathrm{H}$, de Caestecker MP and Yamada Y (2001) Transcriptional cross-talk between Smad, ERK1/2, and p38 mitogen-activated protein kinase pathways regulates transforming growth factor-beta-induced aggrecan gene expression in chondrogenic ATDC5 cells. J Biol Chem 276, 14466-14473

8. Heldin $\mathrm{CH}$, Vanlandewijck $M$ and Moustakas A (2012) Regulation of EMT by TGFbeta in cancer. FEBS Lett 586, 1959-1970

9. Martin TA and Jiang WG (2009) Loss of tight junction barrier function and its role in cancer metastasis. Biochim Biophys Acta 1788, 872-891

10. Matter K and Balda MS (2007) Epithelial tight junctions, gene expression and nucleo-junctional interplay. J Cell Sci 120, $1505-1511$

11. Shen $L$ (2012) Tight junctions on the move: molecular mechanisms for epithelial barrier regulation. Ann N Y Acad Sci 1258, 9-18

12. Harhaj NS and Antonetti DA (2004) Regulation of tight junctions and loss of barrier function in pathophysiology. Int J Biochem Cell Biol 36, 1206-1237

13. Itoh M, Furuse M, Morita K, Kubota K, Saitou M and Tsukita $S$ (1999) Direct binding of three tight junction-associated MAGUKs, ZO-1, ZO-2, and ZO-3, with the $\mathrm{COOH}$ termini of claudins. J Cell Biol 147, 1351-1363

14. Tuomi S, Mai A, Nevo J et al (2009) PKCepsilon regulation of an alpha5 integrin-ZO-1 complex controls lamellae formation in migrating cancer cells. Sci Signal 2, ra32
15. Chen HH, Zhou XL, Shi YL and Yang J (2013) Roles of p38 MAPK and JNK in TGF-beta1-induced human alveolar epithelial to mesenchymal transition. Arch Med Res 44, 93-98

16. Martin TA, Watkins G, Mansel RE and Jiang WG (2004) Loss of tight junction plaque molecules in breast cancer tissues is associated with a poor prognosis in patients with breast cancer. Eur J Cancer 40, 2717-2725

17. Hoover KB, Liao SY and Bryant PJ (1998) Loss of the tight junction MAGUK ZO-1 in breast cancer: relationship to glandular differentiation and loss of heterozygosity. Am J Pathol 153, 1767-1773

18. Kaihara T, Kawamata H, Imura J et al (2003) Redifferentiation and ZO-1 reexpression in liver-metastasized colorectal cancer: possible association with epidermal growth factor receptor-induced tyrosine phosphorylation of ZO-1. Cancer Sci 94, 166-172

19. Kleeff J, Shi X, Bode HP et al (2001) Altered expression and localization of the tight junction protein ZO-1 in primary and metastatic pancreatic cancer. Pancreas 23, 259-265

20. Ni S, Xu L, Huang J et al (2013) Increased ZO-1 expression predicts valuable prognosis in non-small cell lung cancer. Int J Clin Exp Pathol 6, 2887-2895

21. Smalley KS, Brafford $P$, Haass NK, Brandner JM, Brown E and Herlyn M (2005) Up-regulated expression of zonula occludens protein-1 in human melanoma associates with $\mathrm{N}$-cadherin and contributes to invasion and adhesion. Am J Pathol 166, 1541-1554

22. Park MK, You HJ, Lee HJ et al (2013) Transglutaminase-2 induces $\mathrm{N}$-cadherin expression in TGF-beta1-induced epithelial mesenchymal transition via c-Jun-N-terminal kinase activation by protein phosphatase $2 \mathrm{~A}$ down-regulation. Eur J Cancer 49, 1692-1705

23. Brown KA, Aakre ME, Gorska AE et al (2004) Induction by transforming growth factor-beta1 of epithelial to mesenchymal transition is a rare event in vitro. Breast Cancer Res 6, R215-R231

24. Halder SK, Beauchamp RD and Datta PK (2005) A specific inhibitor of TGF-beta receptor kinase, SB-431542, as a potent antitumor agent for human cancers. Neoplasia 7, 509-521

25. Hiraga R, Kato M, Miyagawa S and Kamata T (2013) Nox4-derived ROS signaling contributes to TGF-beta-induced epithelial-mesenchymal transition in pancreatic cancer cells. Anticancer Res 33, 4431-4438

26. Balda MS and Matter K (2000) The tight junction protein ZO-1 and an interacting transcription factor regulate ErbB-2 expression. EMBO J 19, 2024-2033

27. Brysse A, Mestdagt M, Polette M et al (2012) Regulation of CXCL8/IL-8 expression by zonula occludens- 1 in human breast cancer cells. Mol Cancer Res 10, 121-132

28. Xu J, Lim SB, Ng MY et al (2012) ZO-1 regulates Erk, Smad1/5/8, Smad2, and RhoA activities to modulate self-renewal and differentiation of mouse embryonic stem cells. Stem Cells 30, 1885-1900

29. Livak KJ and Schmittgen TD (2001) Analysis of relative gene expression data using real-time quantitative PCR and the 2(-Delta Delta C(T)) Method. Methods 25, 402-408

30. You HJ, LeeJW, Yoo YJ and Kim JH (2004) A pathway involving protein kinase Cdelta up-regulates cytosolic phospholipase $A(2)$ alpha in airway epithelium. Biochem Biophys Res Commun 321, 657-664 